\title{
Volume of sealer in the apical region of teeth filled by different techniques: micro-CT analysis
}

Vanessa Lessa ARAÚJO

Aline Evangelista SOUZA-GABRIEL Antônio Miranda da CRUZ FILHO Jesus Dialma PÉCORA Ricardo Gariba SILVA

Universidade de São Paulo - USP, Dental School of Ribeirão Preto, Department of Restorative Dentistry, Ribeirão Preto, SP, Brazil.
Declaration of Interests: The authors certify that they have no commercial or associative interest that represents a conflict of interest in connection with the manuscript.

\section{Corresponding Author:}

Vanessa Lessa Araúio

E-mail:vanessalessa@usp.br

DOI: 10.1590/1807-3107BOR-2016.vol30.0027

Submitted: Jul 08, 2015

Accepted for publication: Aug 16, 2015

Last revision: Dec 11, 2015

\begin{abstract}
The volume of sealer in the apical $1 \mathrm{~mm}$ of teeth filled using different techniques was evaluated by micro-commuted tomography (micro-CT). Sixty-four maxillary central incisors were prepared using NiTi rotary instruments. Teeth were randomly distributed into four groups according to root canal sealers (AH Plus, Endofill, Sealapex, and Sealer 26) and subdivided into two subgroups according to the filling techniques (active and passive lateral condensation; $\mathrm{n}=8$ each). Subsequently, teeth were examined using the 1174 SkyScan micro-CT device. Images were reconstructed using the NRecon software, and the sealer volume $\left(\mathrm{mm}^{3}\right)$ in the apical region was analyzed using the two-way ANOVA and post-hoc Student-Newman-Keuls test $(\alpha=0.05)$. The lowest volume of sealer was observed in teeth filled with Sealapex $(0.100 \pm 0.009)$ and Endofill $(0.103 \pm 0.010)$. The highest volume was observed in teeth filled with AH Plus $(0.112 \pm 0.008)$ and Sealer 26 $(0.109 \pm 0.018)(p>0.05)$. Regarding the filling technique, a lower sealer volume was observed using the active lateral condensation technique compared with that using the passive lateral condensation technique $(0.100 \pm 0.010$ vs. $0.111 \pm 0.012)(p<0.05)$. Therefore, the lowest volume of sealer was observed in teeth filled with Sealapex and Endofill using the active lateral condensation technique.
\end{abstract}

Keywords: X-Ray Microtomography; Root Canal Filling Materials; Endodontics.

\section{Introduction}

The anatomy complexity of the root canal system is a challenge and a clinical difficulty for the endodontic therapy. The apical portion of the canal has numerous ramifications, highlighting the need for achieving adequate sealing to avoid recontamination. ${ }^{1}$

The efficiency of a filling material in properly sealing the root canal is determined by its physical properties and handling characteristics. ${ }^{2,3}$ No other filling material has been as successful and widely accepted as gutta-percha, probably owing to its favorable properties such as biocompatibility, plasticity, radiopacity, and easy insertion and removal from the root canal. ${ }^{4,5,6,7,8}$ Despite these beneficial features, gutta-percha shows no adhesion to dentine, resulting in gaps between the cone and root canal walls. ${ }^{9}$ In root canal treatment, the ideal result is to insert the largest volume of gutta-percha and minimum amount of sealer inside 
the root canal, enabling the sealer to penetrate the irregularities of the dentine walls and tubules., ${ }^{3,0,11}$

Among the filling techniques pertaining to the root canal system, the lateral condensation (passive or active) technique is widely used ${ }^{7,6,12}$ and offers the advantage of a controlled placement of gutta-percha into the root canal., ${ }^{2,7}$ The passive lateral condensation technique does not require the application of external pressure using finger spreaders and may allow premature coronal filling because the coronal portion of the accessory cone has a larger diameter ${ }^{10}$. However, the active lateral condensation technique requires the use of finger spreaders that offer more space between the main cone and the root canal walls, which allows filling with a greater number of accessory cones adapted to the root canal. ${ }^{10,13,14}$

Micro-computed tomography (micro-CT) is a nondestructive three-dimensional imaging technique that has been adopted for use in endodontics to analyze the interfacial quality of root fillings. ${ }^{15}$ This technology offers a reproducible technique that can be applied for the three-dimensional assessment of the root canal system. ${ }^{15,16}$ Some studies have reported good results using micro-CT to evaluate the filling quality pertaining to different techniques. ${ }^{17,18,19}$ However, it is important to evaluate the sealer volume in the root fillings owing to its properties that can influence the filling, particularly in the apical region. Therefore, the aim of this in vitro study was to evaluate the volume of different root canal sealers in the apical $1 \mathrm{~mm}$ of the working length using lateral condensation techniques (passive or active) through micro-CT. The null hypothesis tested was that all the filling techniques would be effective in endodontic treatment using different sealers.

\section{Methodology}

\section{Tooth selection}

The experimental protocol was approved by the local ethics committee on human research (\#20872013.0.0000.5419). Maxillary human incisors, stored in $0.1 \%$ thymol solution at $4^{\circ} \mathrm{C}$, were washed under running water for $24 \mathrm{~h}$ to eliminate thymol residues. Teeth were examined macroscopically and radiographed in the bucco-palatal direction to select
64 incisors with fully formed roots, a single canal without calcifications, reabsorption or curvatures, a pulp chamber without calcifications or caries, and the absence of previous endodontic treatment. All procedures were performed by a single operator.

\section{Root canal preparation}

The pulp chamber was accessed and a size $15 \mathrm{~K}$-file (Dentsply Maillefer, Baillagues, Switzerland) was introduced into each canal until its tip was visible at the apical foramen. The working length was established by subtracting $1 \mathrm{~mm}$ from this length. Roots with a diameter of $250 \mu$ at the working length were selected. The coronal third of the canals was preflared using LA Axxess burs (SybronEndo Corporation, Orange, USA) at low speed, following the sequence 20.06, 35.06, and 45.06. Next, the canals were prepared using $\mathrm{K}^{\circledR}{ }^{\circledR}$ rotary instruments (SybronEndo Corporation) in the following sequence: $25 / .02,25 / .04,25 / .06,30 / .02$, $30 / .04,25 / .06,35 / .02,25 / .06,40 / .02,25 / .06,45 / .02,25 / .06$, $50 / .02,25 / .06,55 / .02,25 / .06$, and 60.02. The apical stop was prepared using the last instrument. Throughout preparation, the canals were irrigated with $2 \mathrm{~mL}$ of $1 \%$ sodium hypochlorite (Ciclo Farma, Serrana, Brazil) every time the rotatory instrument was changed, rinsed with $5 \mathrm{~mL}$ of $17 \%$ ethylenediaminetetraacetic acid (EDTA) (Biodinâmica, Ibiporã, Brazil) for 5 min, flushed with $5 \mathrm{~mL}$ of distilled water, and dried with paper points (Dentsply Maillefer).

\section{Teeth distribution}

After preparation, the 64 roots were randomly assigned to four groups according to the root canal sealer: AH Plus (Dentsply Detrey $\mathrm{GmbH}$, Konstanz, Germany), Endofill (Dentsply Maillefer), Sealapex (SybronEndo), and Sealer 26 (Dentsply Maillefer). The roots were then distributed into two subgroups according to the filling technique $(\mathrm{n}=8)$ : active and passive lateral condensation.

\section{Root canal fillings}

The gutta-percha cone with the same size of the master apical file (60/.02) was chosen after confirming its diameter using a calibrating ruler. Three tests were performed to check the gutta-percha master cone for each root canal: visual, the cone tip reached the 
full working length; tactile, tug back was felt when the cone tip was at the apical length indicating a tight fit in the apical end of the working length; and radiographic, the cone tip reached the radiographic working length.

In specimens that were filled using the passive lateral condensation technique, the main cone was covered with sealer and inserted into the root canal, followed by passive placement of R7 accessory cones (Dentsply Maillefer), which were also covered with sealer. After radiographic confirmation, the guttapercha was cut using a heated Paiva plugger and the vertical condensation technique was performed. In teeth filled using the active lateral condensation technique, the main cone was covered with sealer and inserted into the root canal with the aid of a finger spreader (Dentsply Maillefer) to create space for the accessory cones. Subsequently, the vertical condensation technique was performed.

After filling, excess sealer in the pulp chamber was removed using cotton pellets and alcohol. All specimens were sealed with non-eugenol-containing temporary cement (Coltosol; Vigodent S/A Indústria e Comércio, Rio de Janeiro, Brazil) and stored at $37^{\circ} \mathrm{C}$ for a time equivalent to $3 \times$ the setting time of sealer.

\section{Micro-CT analysis}

The specimens were scanned using a micro-CT device (SkyScan 1174v2; Bruker-microCT, Kontich, Belgium) with the following settings: $50 \mathrm{kV}, 800 \mathrm{~mA}$, isotropic resolution of $16.7 \mu \mathrm{m}$, and projections from $360^{\circ}$ acquisition rotation. Images of the volume of gutta-percha and sealer in the filling mass of each specimen were reconstructed using the NRecon v.1.6.3 software (Bruker-microCT). Axial cross-sections of the inner structure of the samples were attained using the 60 sections obtained from the first slice that showed the main cone of gutta-percha; these sections were marked as the region of interest, equating to approximately $1 \mathrm{~mm}$ and referring to the apical $1 \mathrm{~mm}$ of the working length, which is the region that is most difficult to fill owing to the presence of numerous ramifications. The CTAn v.2.2.1 software (Bruker-microCT) was used to evaluate the threedimensional volume of the apical $1 \mathrm{~mm}$ of the working length. Volume was calculated as binarized objects within the volume of interest.

Three-dimensional models were reconstructed from the source images using automatic segmentation and surface modeling with the CTAn v.2.2.1 software. The CTVol v.2.4 software (Bruker-microCT) was used for the visualization and qualitative evaluation of the root canal fillings of the specimens (Figure). Micro-CT imaging was performed to determine the volume of sealer in the filling and was estimated in the apical $1 \mathrm{~mm}$ of the working length; this length corresponds to the first 60 micro-CT slices (60 slices $\times 16.7 \mu \mathrm{m}=1002 \mu \mathrm{m} \pm 1 \mathrm{~mm}$ ) that were considered to be the region of interest during analysis.

\section{Statistical analysis}

Two-way analysis of variance was performed with the volume of sealer and filling technique as independent variables. Multiple comparisons were performed using the post-hoc Student-Newman-Keuls test at a significance level of 5\%. The SPSS software version 19 (SPSS Inc., Chicago, USA) was used for all statistical analyses.

\section{Results}

There were significant differences in the volume of sealer $(p=0.023)$, filling technique $(p<0.05)$, and interactions among factors $(p=0.015)$. Teeth filled with Sealapex and Endofill had a lower volume of sealer at the apical $1 \mathrm{~mm}$ of the working length as compared with those filled with AH Plus and Sealer 26 ( $\mathrm{p}<0.05)$ (Table).

Regarding the filling techniques, the active lateral condensation technique required a lower volume of sealer than the passive lateral condensation technique $(0.100 \pm 0.010$ vs. $0.111 \pm 0.012)(\mathrm{p}<0.05)$. There was no significant difference in the volume of sealer using the active lateral condensation technique ( $p>0.05)$. In the passive technique, Sealapex had the lowest volume of sealer, similar $(p>0.05)$ to Endofill. Teeth filled with Sealer 26 had the highest volume $(p<0.05)$, similar to AH Plus. The volumes of AH Plus and Endofill were statistically similar ( $p>0.05)$ (Table). 
A

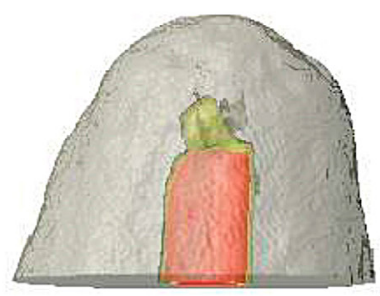

C

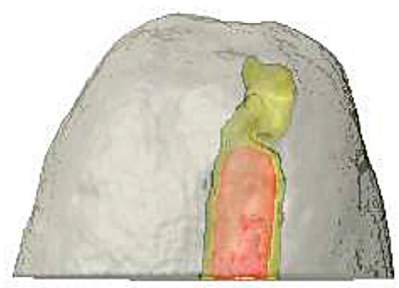

$\mathbf{E}$

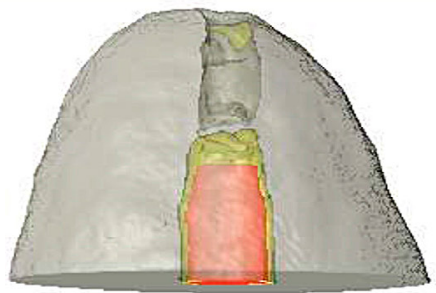

G

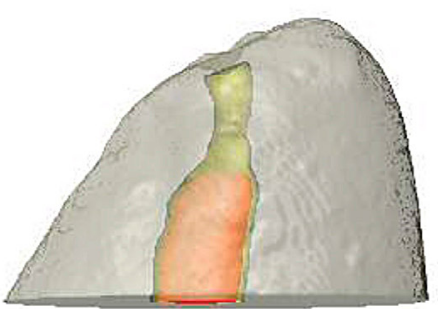

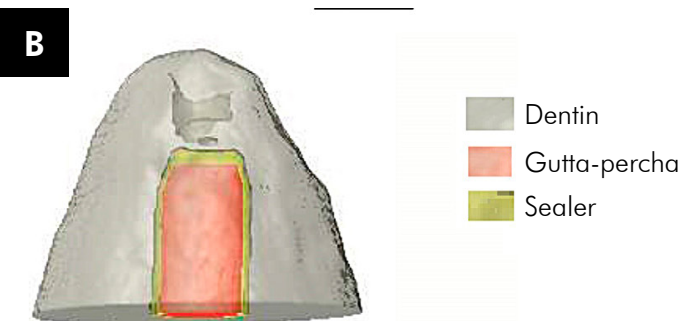

D
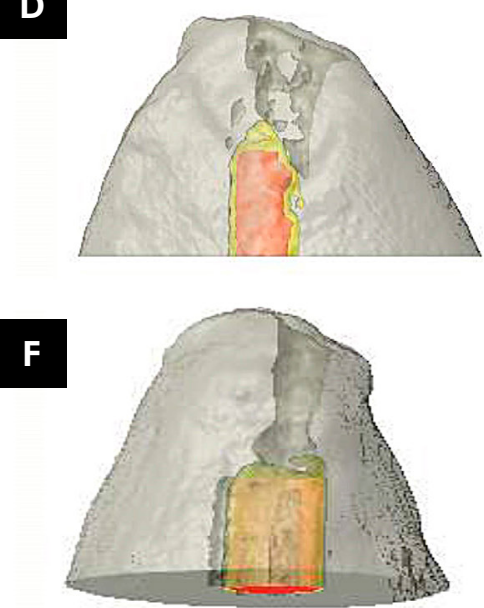

H

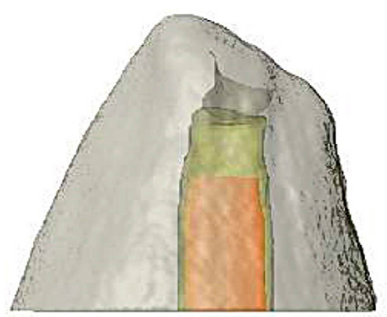

Figure. Three-dimensional models reconstructed from images obtained in the apical $1 \mathrm{~mm}$ of the fillings: (A) Sealapex using the active lateral condensation technique. (B) Sealapex using the passive lateral condensation technique. (C) Sealer 26 using the active lateral condensation technique. (D) Sealer 26 using the passive lateral condensation technique. (E) AH Plus using the active lateral condensation technique. (F) AH Plus using the passive lateral condensation technique. (G) Endofill using the active lateral condensation technique. $(\mathrm{H})$ Endofill using the passive lateral condensation technique.

Table. Means and standard deviations of the sealer volume considering different techniques and root canal sealers $\left(\mathrm{mm}^{3}\right)$.

\begin{tabular}{lcc}
\hline \multirow{2}{*}{ Root canal sealers } & \multicolumn{2}{c}{ Technique } \\
\cline { 2 - 3 } AH Plus & $0.115 \pm 0.009$ & $0.108 \pm 0.005 \mathrm{Aa}$ \\
Endofill & $\mathrm{Abc}$ & Active \\
& $0.108 \pm 0.008$ & $0.099 \pm 0.011 \mathrm{Aa}$ \\
Sealapex & $\mathrm{Aab}$ & \\
Sealer 26 & $0.101 \pm 0.005 \mathrm{Aa}$ & $0.098 \pm 0.012 \mathrm{Aa}$ \\
\hline
\end{tabular}

*Different letters indicate significant difference between groups $(p<0.05)$. Uppercase letters, comparison between the columns for each filling technique and lowercase letters, comparison between lines for different groups of sealers.

\section{Discussion}

In root canal treatment, sealer plays an important role in filling the gaps between the dentine walls and gutta-percha. ${ }^{20}$ Filling techniques have been developed to minimize the thickness of the sealer and increase the volume of gutta-percha in the root canal. ${ }^{11,21}$ Several authors have suggested the evaluation of the percentage of gutta-percha as a filling quality parameter. ${ }^{22,10}$ In this study, the sealer volume was analyzed according to its influence on filling. A thin layer of sealer can decrease gaps that form because 
of sealer dissolution, particularly in the apical region that is more susceptible to microleakage.,

Numerous in vitro investigations have evaluated filling techniques by comparing different variables. In the current study, we performed micro-CT to analyze the volume of sealer. In addition, micro-CT can distinguish gutta-percha and sealer based on different colors.

The sealer film thickness and gutta-percha component may be of particular relevance when filling of the apical root is analyzed. Filling of the apical root should provide a seal, particularly because after space preparation, only the apical root filling of 3 or $4 \mathrm{~mm}$ in length remains. ${ }^{23}$ Moreover, studies have shown that numerous lateral canals are present in the apical third. The confirmed solubility of sealers implies the necessity to limit its presence to a thin film. ${ }^{17}$ In this study, the lowest volume of sealer in the apical $1 \mathrm{~mm}$ was observed in teeth filled with Sealapex and Endofill, suggesting a better sealing ability. This result could be ascribed to the fact that these sealers have a higher flow rate than the other sealers studied. ${ }^{24,25,26}$. The flowability of the sealers is an important property that can determine the extent of filling of anatomical irregularities and spaces between the main cone and accessory cones to improve the effectiveness of root canal fillings..$^{21,27,28}$ Previous studies also reported good results using Sealapex with regard to its sealing ability, ${ }^{29}$ flowability, ${ }^{30}$ and viscosity. ${ }^{31}$

The better performance of Sealapex can also be explained by the presence of calcium hydroxide in its composition. The mechanism of action of calcium hydroxide is achieved through the ionic dissociation of $\mathrm{Ca}^{2+}$ and $\mathrm{OH}^{-}$ions and its effects on biological tissues, which causes the induction of hardtissue deposition and also inhibits the migration of microorganisms to the root canal. ${ }^{20}$ The addition of calcium hydroxide in root canal sealers improves the physicochemical properties, mainly owing to a decrease in the sealer flow rate. ${ }^{32}$ The hydroxyl group has a very high $\mathrm{pH}$ that encourages apical repair in filled teeth and active calcification. ${ }^{33}$

In the present study, teeth filled with Sealer 26 and $\mathrm{AH}$ Plus showed the highest volume of sealer, probably owing to the higher viscosity of the epoxy resin-based sealer, which was confirmed in a previous study. ${ }^{28}$ Previous reports on physicochemical properties highlighted that the presence of epoxy resin is responsible for increasing sealer viscosity. ${ }^{21,26}$

In this study, we also observed a lower volume of sealer using the active lateral condensation technique than that using the passive lateral condensation technique, regardless of the sealer used, probably because of the use of finger spreaders in the active lateral condensation technique to create space for inserting a higher number of gutta-percha cones into the root canal, 13,34 thereby decreasing the volume of gaps that occur because of sealer dissolution and the lack of filling root canal irregularities. ${ }^{22,35}$ Although a spreader cannot reach the apical $1 \mathrm{~mm}$, it exerts a force that results in changes in the apical $1 \mathrm{~mm}$. Some authors have also found that gutta-percha occupied a greater amount of the filling when using the lateral condensation technique..$^{22,35}$ The sealers assessed in this study had the same performance when using the active lateral condensation technique to fill the root canal, as previously observed. ${ }^{34}$

Some studies comparing the lateral condensation technique with other techniques revealed that this technique tended to seal the root canal better than the other techniques such as the hybrid technique in the apical third..$^{19}$ Other studies reported inconsistent findings on the quality of different root filling techniques. De-Deus et al. ${ }^{17}$ examined the percentage of gutta-percha filled areas in oval-shaped canals of 80 mandibular incisors. Teeth were randomly divided into four experimental groups, including the cold and warm lateral condensation techniques (McSpadden thermomechanical compaction, Continous Wave, and Thermafil). The results showed a significantly greater gutta-percha filled area for all thermoplasticized techniques compared with the lateral condensation technique. Ozawa et al. ${ }^{18}$ compared obturation techniques (single-cone, lateral condensation, and Thermafil) in irregular oval canals. The roots were assessed in thirds of the length, which revealed that in the middle and coronal third, Thermafil had the lowest percentage of sealer and the highest volume of filling material, whereas in the apical third, the filling material was generally well adapted to the canal wall for all techniques. 
Micro-CT is considered as the gold standard for the analysis of instrumentation and filling. However, this technique requires preliminary settings of various parameters for the acquisition of reliable results. During processing, filters are used to absorb low energy radiation to reduce the effect of beam hardening. ${ }^{36}$ Even with the filters, there is always a residual effect of beam hardening that can be corrected using the NRecon v.1.6.4 software during specimen reconstruction. Another aspect considered for scanning of each experimental group was the correction of the acquisition field (flat field) to improve the quality of the obtained digital image pertaining to the type and filter size used and to remove any generated artifacts. ${ }^{37}$ Each of these corrections was performed to ensure the accuracy of the results.

Further research is necessary to fully demonstrate the potencial of micro-CT to evaluate canal filling and

\section{References}

1. Pablo OV, Estevez R, Sánchez MP, Heilborn C, Cohenca N. Root anatomy and canal configuration of the permanent mandibular first molar: a systematic review. J Endod. 2010;36(12):1919-31. doi:10.1016/j.joen.2010.08.055

2. Deitch AK, Liewehr FR, West LA, Patton WR. A comparison of fill density obtained by supplementing cold lateral condensation with ultrassonic condensation. J Endod. 2002;28(8):665-7. doi:10.1097/00004770-200209000-00009

3. Li G-H, Niu L-N, Zhang W, Olsen M, De-Deus G, Eid AA, et al. Ability of new obturationmaterials toimprove theseal of theroot canal system: a review. Acta Biomater. 2014 Mar;10(3):1050-63. doi:10.1016/j.actbio.2013.11.015. Epub 2013 Dec 7.

4. Gulsahi K, Cenheli ZC, Onay EO, Tasman-Dagli F, Ungor $\mathrm{M}$. Comparison of the area of resin-based sealer and voids in roots obturated with resilon and gutta-percha. J Endod. 2007;33(11):1338-41. doi:10.1016/j.joen.2007.06.015

5. James BL, Brown CR, Legan JJ, Moore BK, Vail MM. An in vitro evaluation of the contents of root canals obturated with gutta percha and AH-26 sealer or resilon and epiphany sealer. J Endod. 2007;33(11):1359-63. doi:10.1016/j.joen.2007.07.021

6. Keles A, Ahmetoglu F, Ocak MS, Dayi B, Bozkurt A, Orucoglu $\mathrm{H}$. Comparative analysis of three different filling techniques and the effects of experimental internal resorptive cavities on apical microleakage. Eur J Dent. 2014;8(1):32-7. doi:10.4103/1305-7456.126237

7. Lea CS, Apicella MJ, Mines P, Yancich P, Parker MH. Comparison of the obturation density of cold lateral compaction versus warm vertical compaction using the compare the efficacy of this filling technique with other techniques using different sealers to improve the sealing of the root canal systems.

\section{Conclusion}

The results of this study showed that teeth filled with Sealapex and Endofill showed the lowest volume of sealer. The active lateral condensation technique resulted in a lower volume of sealer in root canals compared with the other techniques.

\section{Acknowledgements}

The authors have no conflicts of interest associated with this study and wish to thank the study participants joining and also appreciate the support provided by Coordenação de Aperfeiçoamento do Pessoal de Nível Superior - CAPES.

continuous wave of condensation technique. J Endod. 2005;31(1):37-9. doi:10.1097/01.DON.0000129037.75547.80

8. Miner MR, Berzins DW, Babcall JK. A comparison of termal properties between gutta-percha and a synthetic polymer based root canal filling material (Resilon). J Endod. 2006;32(7):683-6. doi:10.1016/j.joen.2006.01.008

9. Chandrasekhar V, Morishetty PK, MetlaSL, Raju C. Expansion of gutta-percha in contact with various concentrations of zinc oxide-eugenol sealer: a three-dimensional volumetric study. J Endod. 2011;37(5):697-700. doi:10.1016/j.joen.2011.02.014

10. Souza EM, Wu MK, van derSluis LW, Leonardo RT, Bonetti-FilhoI, Wesselink PR. Effect of filling technique and root canal area on the percentage of guta-percha in laterally compacted root fillings. Int Endod J. 2009;42(9):719-26. doi:10.1111/j.1365-2591.2009.01575.x

11. Pane ES, Palamara JEA, Messer HH. Behavior of resin-based endodontic sealer cements in thin and thick films. Dent Mater. 2012;28(9):e150-9. doi:10.1016/j.dental.2012.04.012

12. Robia G. Comparative radiographic assessment of root canal obturation quality: manual verses rotary canal preparation technique. Int J Biomed Sci. 2014;10(2):136-42.

13. Pinheiro BC, BramanteAS,HussneRP.Influence of thepenetration of instruments, used in the active lateral condensation, in the quality of root canal filling. J Appl Oral Sci. 2003;11(3):186-91. doi:10.1590/S1678-77572003000300006. Portuguese.

14. Dulaimi SF, Wali Al-Hashimi MK. A comparison of spreader penetration depth and load required during lateral condensation in teeth prepared using various root canal preparation techniques. Int Endod J. 2005 Aug;38(8):510-5. doi:10.1111/j.1365-2591.2005.00969.x 
15. Moeller L, Wenzel A, Wegge-Larsen AM, Ding M, Kirkevang LL. Quality of root fillings performed with two root filling techniques. An in vitro study using micro-CT. Acta Odontol Scand. 2013;71(3-4):689-96. doi:10.3109/00016357.2012.715192

16. Somma F, Cretella G, Carotenuto M, Pecci R, Bedini R, De Biasi M, et al. Quality of thermoplasticized and single point root fillings assessed by micro-computed tomography. Int Endod J. 2011;44(4):362-9. doi:10.1111/j.1365-2591.2010.01840.x

17. De-Deus G, Gurgel-Filho ED, Magalhães KM, Coutinho-Filho T. A laboratory analysis of gutta-percha-filled area obtained using Thermafil, System B and lateral condensation. Int Endod J. 2006;39(5):378-83. doi: 10.1111/j.1365-2591.2006.01082.x

18. Ozawa T, Taha N, Messer HH. A comparison of techniques for obturing oval-shaped root canals. Dent Mater J. 2009;28(3):290-4. doi:10.4012/dmj.28.290

19. Moeller L, Wenzel A, Wegge-Larsen AM, Ding M, Kirkevang LL. Quality of root fillings performed with two root filling techniques. An in vitro study using micro-CT. Acta Odontol Scand. 2013;71(3-4):689-96. doi:10.3109/00016357.2012.715192

20. Mohammed M, Saujanya KP, Deepak J, Sangameshwar S, Arun A, Laxmi U, Mahnoor K. Role of calcium hydroxide in endodontics: a review. Glob J Med Public Health. 2012;1(1):53-7.

21. Venturi M. An ex vivo evaluation of a gutta-percha filling technique when used with two endodontic sealers: analysis of the filling of main and lateral canals. J Endod. 2008;34(9):1105-10. doi:10.1016/j.joen.2008.06.017

22. Jarret IS, Marx D, Covey D, Karmazin D, Lavin M, Gound T. Percentage of canals filled in apical cross sections - an in vitro study of seven obturation techniques. Int Endod J. 2004;37(6):392-8. doi: 10.1111/j.1365-2591.2004.00821.x

23. Wu M, Van der Sluis LW, Wesselink PR. A preliminary study of the percentage of gutta-percha-filled area in the apical canal filled with vertically compacted warm gutta-percha. Int Endod J. 2002;35(6):527-35. doi:10.1046/j.1365-2591.2002.00522.x

24. Scelza MFZ, Scelza P, Costa RF, Câmara A. Comparative study the physical properties of flow, solubility and disintegration of some root canal sealers. Pesqui Bras Odontopediatria Clin Integr. 2006;6(3):243-7.

25. Faria-Júnior NB, Massi S, Croti HR, Gutierrez JCR, Dametto FR, Vaz LG. Comparative assessment of the flow rate of root canal sealers. Rev Odonto Cienc. 2010;25(2):170-3. doi:10.1590/S1980-65232010000200012
26. Marin-Bauza GA, Silva-Sousa YTC, Cunha SA, Rached-Junior FJA, Bonetti-Filho I, Sousa-Neto MD, Miranda CES. Physicochemical properties of endodontic sealers of different bases. J Appl Oral Sci. 2012;20(4):455-61. doi:10.1590/S1678-77572012000400011

27. Marciano MA, Guimarães BM, Ordinola-Zapata R, Bramante CM, Cavenago BC, Garcia RB, et al. Physical properties and interfacial adaptation of three epoxy resin-based sealers. J Endod. 2011;37(10):1417-21. doi:10.1016/j.joen.2011.06.023

28. Zhou HM, Shen Y, Zheng W, Li L, Zheng YF, Haapasalo M. Physical properties of 5 root canal sealers. J Endod. 2013;39(10):1281-6. doi:10.1016/j.joen.2013.06.012

29. Cobankara FK, Orucoglu H, Sengun A, Belli S. The quantitative evaluation of apical sealing of four endodontic sealers. J Endod. 2006;32(1):66-8. doi:10.1016/j.joen.2005.10.019

30. Almeida VF, Gomes BP, Ferraz CC, Souza-Filho FJ, Zaia AA. Filling of artificial lateral canals and microleakage and flow of five endodontic sealers. Int Endod J. 2007;40(9):692-9. doi:10.1111/j.1365-2591.2007.01268.x

31. Chang SW, Lee YK, Zhu Q, Shon WJ, Lee WC, Kum KY, et al. Comparison of the rheological properties of four root canal sealers. Int J Oral Sci. 2014;7(1):56-61. doi:10.1038/ijos.2014.33

32. Hosoya N, Kurayama H, Lino F, Arai T. Effects of calcium hydroxide on physical and sealing properties of canal sealers. Int Endod J. 2004;37(3):178-84. doi:10.1111/j.0143-2885.2004.00781.x

33. Desai S, Chandler N. Calcium hydroxide-based root canal sealers: A review. J Endod. 2009;35(4):475-80. doi:10.1016/j.joen.2008.11.026

34. Estrela C, Pesce HF, Sidney GB, Figueiredo JA. Apical leakage using various sealers and root canal filling techniques. Braz Dent J. 1994;5(1):59-63.

35. Gordon MPJ, Love RM, Chandler NP. An evaluation of.06 tapered gutta-percha cones for filling of.06 taper prepared curved root canals. Int Endod J. 2005;38(2):87-96. doi:10.1111/j.1365-2591.2004.00903.x

36. Naranjo V, Lloréns R, Alcañiz M, Lopéz-Mir F. Metal artifact reduction in dental CT images using polar mathematical morphology. Comput Methods Programs Biomed. 2011;102(1):64-74. doi:10.1016/j.cmpb.2010.11.009

37. Sijbers J, Postnov A. Reduction of ring artefacts in high resolution micro-CT reconstructions. Phys Med Biol. 2004;49(14):N247-53. doi:10.1088/0031-9155/49/14/N06 